\title{
A Simple Synthesis of Higher Refractive Index Polymeric Nanocomposite Containing the Pendant ZnS Nanocrystals Capping Different Amount of Mercaptoethanol
}

\author{
Xinxin Li and Jinku Xu \\ School of Chemistry and Pharmaceutical Engineering, Qilu University of Technology (Shandong Academy of Sciences), \\ Jinan 250353, China \\ Correspondence should be addressed to Jinku Xu; jkxu2003@126.com
}

Received 13 February 2020; Accepted 27 June 2020; Published 11 August 2020

Academic Editor: Shafiul Chowdhury

Copyright ( $) 2020$ Xinxin Li and Jinku Xu. This is an open access article distributed under the Creative Commons Attribution License, which permits unrestricted use, distribution, and reproduction in any medium, provided the original work is properly cited.

\begin{abstract}
In this paper, three kinds of ZnS NPs capping different amount of mercaptoethanol (ME) were synthesized, and the effect of capping amount on ZnS NPs was studied, indicating that the capping amount of ME on ZnS surface decreases, while ZnS size increases as the decrease of added capping agent in synthesis process, and ZnS NP capping middle amount of ME ( 27.7 wt\%) shows a highest apparent refractive index (RI) value. ZnS NPs were composited into polymeric matrices by a simple "one-step" thermocuring method characterized by adding a small amount of functional monomer of glycidyl methacrylate (GMA) and solvent of N,N-dimethylformamide (DMF) The reaction mechanism, studied by ${ }^{1} \mathrm{H}$ NMR spectra, indicates that the epoxy of GMA monomer can be easily opened and chemically grafted on ME-capped ZnS surface under the catalysis of DMF, and then copolymerized with other monomer. By the route, $\mathrm{ZnS}$ NPs can be composited into pure poly(N,N-dimethylacrylamide)-type (DMA-type), DMA-type copolymer, and DMA-free matrices to fabricate transparent films, and its RI value can be improved by either optimizing capping amount on $\mathrm{ZnS}$ surface or increasing $\mathrm{ZnS}$ content in the nanocomposites. The RI value of resulting dried nanocomposites can be improved to 1.764 by compositing $80 \mathrm{wt} \% \mathrm{ZnS}$ capping middle amount of ME.
\end{abstract}

\section{Introduction}

High refractive index (RI) optical materials have extensive applications in lenses, prism, waveguides, and light-emitting diodes (LEDs) [1-3], and great progress has been made to synthesize high RI materials. An effective way is grafting high RI organic molecules with aromatic [4], fused ring [5] groups, or heteroatoms [6] in the optical materials. The other promising strategy is compositing high RI inorganic nanoparticles (NPs) into polymer matrices, because many kinds of high RI inorganic NPs, e. g., quantum dots (QDs), have been successfully synthesized, and its size less than $10 \mathrm{~nm}$ can ensure transparency of resulting nanocomposite materials. Two main approaches have been developed to composite inorganic nanoparticles in polymeric matrices including either in situ formation of inorganic NPs in the polymeric matrix or bulk polymerization of organic monomer solution in the present of premade nanoparticles. The latter approach is usually proved to be more effective, because it can provide full synthetic control over both the nanoparticles and the polymeric matrices.

It is crucial to maintain high particle dispersion homogeneity in nanocomposites for optical application. However, nanoparticles tend to aggregation in polymeric matrices, resulting in transmittance loss due to light scattering. Two methods can be used to reduce particle aggregation either bonded covalently nanoparticles on the polymeric skeleton or embedded physically nanoparticles in special polymeric matrices that interact with the nanoparticles. Usually, the former method can ensure a more homogeneous intermixing 
between organic and inorganic components, because stronger interaction from covalent bond can effectively block nanoparticle aggregation.

ZnS NPs has high RI (2.36 at $620 \mathrm{~nm})$ and low absorption coefficient (400-1400 nm), and it can be composited into polymeric matrices to prepare high RI nanocomposite film. Moreover, $\mathrm{ZnS}$ can also be used as a higher band-gapped shell material around QDs to improve the fluorescence efficiency and stability of nanocrystals due to decreased surface defects [7]. Nowadays, many kinds of quantum dots such as CdS [8], CdSe [9], CuInS2 [10], and ZnSe [11] have been wrapped $\mathrm{ZnS}$ shell material. Therefore, it is highly expected to develop novel approach to composite ZnS NPs in all kinds of polymeric matrices. Poly $(\mathrm{N}, \mathrm{N}$-dimethylacrylamide) is the most commonly used polymeric matrices embedding physically ZnS NPs [12]. We have also bound typical $\mathrm{ZnS}$ nanocrystal in many kinds of polymers to prepare high RI and transparent ZnS-polymer nanocomposite films. However, a large amount of capping agent on $\mathrm{ZnS}$ surface (about $37 \mathrm{wt} \%$ ) limits further RI improvement of resulting nanocomposite films.

Capping agents are well recognized as a key factor in synthesis and manipulation of quantum dot nanocrystals [13], in which capping agent maintain a dynamic bonding with the surface of nanocrystals at high reaction temperature above $250^{\circ} \mathrm{C}$, ensuring a sufficient coverage of capping agent on a nanocrystal at a given moment resulting in a good solution stability [14]. Many kinds of capping agents have been bound on the surface of quantum dots, and research shows that capping agent plays also integral role in the function of the nanocrystal, such as photoluminescence (PL) properties of semiconductor nanocrystals [15]. However, to our knowledge, the effect of capping amount on nanocrystal structure and its RI value is rarely reported.

In this paper, three kinds of ZnS NPs capping different amount of ME were synthesized, and the effects of capping amount on the size, crystal structure, and refractive index of $\mathrm{ZnS}$ NPs were studied for the first time. Furthermore, ZnS NPs were composited into polymeric matrices to fabricate high RI transparent nanocomposites by a novel, simple, and universal route. The effect of capping amount on the RI value of the resulting nanocomposites was also studied emphatically. The paper involves the design and optimization of the nanoparticle with different amount capping agent and polymeric monomer as well as a suitable polymerization process. The approach has been proved to be effective in the fabrication of both DMA-type and DMA-free nanocomposites with higher RI value by compositing ZnS NPs with middle capping amount of ME.

\section{Experimental Section}

2.1. Materials. Zinc acetate dehydrate $\left(\mathrm{Zn}(\mathrm{Ac})_{2} \bullet 2 \mathrm{H}_{2} \mathrm{O}\right)$, thiourea, and dibutyltin dilaurate (DBTDL) were purchased from Damao Chemicals (Tianjin, China); mercaptoethanol (ME) was purchased from Aladdin Chemical Reagent Co., Ltd. (Shanghai, China); methyl methacrylate (MMA), N, Ndimethylacrylamide (DMA), 2-isocyanatoethyl methacrylate, 2-hydroxyethyl methacrylate (HEMA), glycidyl methacrylate
(GMA), and azobisisobutyronitrile (AIBN) were purchased from SA Chemical Technology Co., Ltd. (Shanghai, China).

\subsection{Synthesis of ME-Capped and Polymerizable-Group-Capped $\mathrm{ZnS} N P S$}

2.2.1. ME-Capped ZnS NPs. Three kinds of ZnS nanoparticles, with different capping amount of ME, were synthesized according to a modified literature method [16]. Firstly, $\mathrm{Zn}(\mathrm{Ac})_{2} \bullet 2 \mathrm{H}_{2} \mathrm{O}(5.5 \mathrm{~g}, 0.025 \mathrm{~mol})$, thiourea $(1.375 \mathrm{~g}$, $0.018 \mathrm{~mol})$, and different amount of $\mathrm{ME}(1.46 \mathrm{~g}, 2.18 \mathrm{~g}$, $2.92 \mathrm{~g}$ ) were, respectively, dissolved in $150 \mathrm{~mL} \mathrm{~N}, \mathrm{~N}$-dimethylformamide (DMF) in a $250-\mathrm{mL}$ three-necked round-bottom flask to obtain clear solution. Then, the solution was refluxed $10 \mathrm{~h}$ at $160^{\circ} \mathrm{C}$ under continuous magnetic stirrer and nitrogen protection. The resultant solution was concentrated to $20 \mathrm{~mL}$ using rotary evaporation under vacuum at $30^{\circ} \mathrm{C}$, and then precipitated in excess ethanol to obtain crude white $\mathrm{ME}$ capped ZnS NPs. The crude ZnS NPs was dispersed in $20 \mathrm{~mL}$ DMF, and then reprecipitated in excess ethanol again. Finally, the white precipitation was collected and washed thoroughly with methanol before dried in vacuum at $30^{\circ} \mathrm{C}$. Three kinds of $\mathrm{ZnS}$ NPs with varying amount of ME from low to high are named as $\mathrm{ZnS}_{1}, \mathrm{ZnS}_{2}$, and $\mathrm{ZnS}_{3}$, respectively.

\subsubsection{Polymerizable-Group-Capped ZnS NPs. Polymerizable-} group-capped $\mathrm{ZnS}$ was synthesized according to our previous route $[17,18]$. Briefly, ME-capped ZnS NPs (3g) and one drop of DBTDL were dispersed in $75 \mathrm{~mL} \mathrm{DMF}$, in which DMF solution of 2-isocyanatoethyl methacrylate $(0.3 \mathrm{~g}$ in $15 \mathrm{~mL}$ DMF) was added drop by drop in half an hour, and then, the solution was kept at $30^{\circ} \mathrm{C}$ for $2.5 \mathrm{~h}$ under continuous stirring and ultrasound. Finally, the solution was concentrated to $10 \mathrm{~mL}$ by vacuum distillation, and then precipitated and washed with excess methanol. Three kinds of polymerizable-group-capped ZnS NPs with different amount of capping agent, named, respectively, as polymerizable-group-capped $\mathrm{ZnS}_{1}$, polymerizable-groupcapped $\mathrm{ZnS}_{2}$, and polymerizable-group-capped $\mathrm{ZnS}_{3}$, were dried in vacuum at $30^{\circ} \mathrm{C}$.

\subsection{Preparation of Transparent ZnS/Polymers Nanocomposite Films}

2.3.1. Pure DMA-Type Nanocomposites Films. ME-capped or polymerizable-group-capped $\mathrm{ZnS}$, with desired weight percent of the final dried nanocomposites, was dispersed in an equal-mass mixture of monomer of DMA and solvent of DMF by ultrasound, in which functional monomer of GMA (10 wt $\%$ of added ME-capped $\mathrm{ZnS}$ ) was added and mixed up by ultrasound. Then, the initiator of AIBN ( $0.5 \mathrm{wt} \%$ of total monomer weight) was added in above solutions and dissolved by ultrasound to obtain a uniform transparent polymerization solution. Finally, the polymerization solution was sealed in the cavity of polypropylene plate molds separated by $0.16-\mathrm{mm}$ thickness polypropylene frame, and then, the molds were placed in oven. The oven was heated up from room temperature to $80^{\circ} \mathrm{C}$ and maintained the temperature for $12 \mathrm{~h}$ to obtain transparent pure DMAtype polymeric nanocomposite films. The films were taken 
off from the molds and removed the solvent of DMF under vacuum at $70^{\circ} \mathrm{C}$ for 4 hours.

2.3.2. DMA-Type Copolymeric Nanocomposite Films. MEcapped $\mathrm{ZnS}$ was dispersed in a mixture of monomer of DMA and solvent of DMF $(1: 1, \mathrm{~m} / \mathrm{m})$ by ultrasound, in which functional monomer of GMA (10 wt $\%$ of ME-capped $\mathrm{ZnS}$ ) was uniformly added by ultrasound. Then, the other monomer of HEMA and initiator of AIBN was orderly added and mixed by ultrasound. Finally, DMA-type copolymeric nanocomposite films were prepared by a similar thermocuring process to pure DMA-type nanocomposites films.

2.3.3. DMA-Free Polymeric Nanocomposites. ME-capped ZnS was dispersed in solvent of DMF by ultrasound, in which functional monomer of GMA (10 wt $\%$ of added ME-capped $\mathrm{ZnS}$ ) was added and mixed up by ultrasound. The resulting solution was maintained in oven at $50^{\circ} \mathrm{C}$ for $3 \mathrm{~h}$, and then, the monomer of MMA and initiator of AIBN were orderly added in and mixed up by ultrasound. Finally, DMA-free polymeric nanocomposites were fabricated by a similar thermocuring process to pure DMA-type nanocomposites.

2.4. Characterization of the Nanocomposite Films Compositing $\mathrm{ZnS} N P$ s. ${ }^{1} \mathrm{H}$ NMR spectra were recorded on a $400 \mathrm{MHz}$ instrument (Bruker AC200) using DMSO-d6 as solvent. $\mathrm{X}$-ray diffraction (XRD) spectra were recorded on a Bruker AXS D8 X-ray diffractometer with a Cu K $\alpha(\lambda=1.5406 \AA)$ source, operated at $40 \mathrm{kV}$ and $20 \mathrm{~mA}$. The $2 \theta$ scanning range was set from $5^{\circ}$ to $90^{\circ}$ with a step size of $0.02^{\circ}$ and at a scanning speed of 1 degree/min. Transmission electron microscopy (TEM) of ZnS NPs was observed with a JEM2100 transmission electron microscope (Japan). Thermogravimetric curves of $\mathrm{ZnS}$ NPs were recorded using a SDT-Q600 TGA instrument in a temperature range from ambient temperature to $600^{\circ} \mathrm{C}$ at a heating rate of $5^{\circ} \mathrm{C} / \mathrm{min}$ under nitrogen protection. The water content in the hydrated nanocomposite hydrogels was calculated by the ratio of weight difference between swollen and dried hydrogels to the weight of swollen hydrogels. The transmittance spectra of nanocomposite hydrogel films were recorded at the wavelength range from $200 \mathrm{~nm}$ to $800 \mathrm{~nm}$ using distilled water as a reference solution. The RI values of dried $\mathrm{ZnS} /$ polymers nanocomposite films were determined by a L116 ellipsometer (gaertner, USA), equipped with a $\mathrm{He}-\mathrm{Ne}$ laser (wavelength $632.8 \mathrm{~nm}$ ). The RI of swollen nanocomposite hydrogels was measured on a WYA Abbe refractometer at $589.3 \mathrm{~nm}$. Mechanical properties of swollen nanocomposite hydrogel films were determined using a Series IX Automated Materials Testing System (Instron Corporation), with a crosshead speed of $20 \mathrm{~mm} / \mathrm{min}$ at room temperature and a relative humidity of $50 \%$.

\section{Results and Discussion}

3.1. Synthesis of ZnS Nanoparticles with Different Amount of Capping Agent. Three kinds of ZnS NPs capping different amount of ME were synthesized by changing the added amount of ME in the process of synthesis. When the mass ratio between capping agent of ME and zinc acetate dehy- drate decreased to $1: 5.5$, white precipitate insoluble in DMF emerged. Increasing the ratio to $1: 3.77$ for the synthesis of $\mathrm{ZnS}$ capping low amount of $\mathrm{ME}\left(\mathrm{ZnS}_{1}\right)$, Tyndall scattering was observed after 1 hour of reaction at $160^{\circ} \mathrm{C}$, and then, the reaction solution turns white, indicating that the $\mathrm{ZnS}$ particle size increases rapidly. As the reaction goes on, the solution slowly turns clear again. Surface capping agent plays a decisive role in the internal structure of nanocrystals [19]. To observe the effect of capping amount on $\mathrm{ZnS}$ nanocrystals, high-resolution transmission electron microscopy (HRTEM) images of $\mathrm{ZnS}_{1-3}$ were performed, and the results were shown in Figures 1(a)-1(c). It can be seen that there is no obvious difference of $\mathrm{ZnS}$ crystalline structure with different capping amount of ME that all show distinct lattice fringes with a distance about $0.275 \mathrm{~nm}$. This is important for ZnS NPs to maintain its attractive high RI properties [20]. HRTEM photography indicates also that $\mathrm{ZnS}$ capping middle amount of $\mathrm{ME}\left(\mathrm{ZnS}_{2}\right)$ shows a wider size distribution, and its nanocrystal shows an appearance from aggregative growth [21] as shown in Figure 1(b).

As shown in Figure 1(d), the X-ray diffraction (XRD) patterns confirm further the crystal structure and crystallinity of ME-capped ZnS NPs capping different amount of ME. Three broad diffraction peaks at $28.7^{\circ}, 47.6^{\circ}$, and $56.4^{\circ}$ were observed, indicating the (111), (220), and (311) planes of $\mathrm{ZnS}$ with zinc blend structure [22]. The size of $\mathrm{ZnS}_{1}$ and $\mathrm{ZnS}_{2}$ is $3.25 \mathrm{~nm}$, and the size of $\mathrm{ZnS}_{3}$ is $2.95 \mathrm{~nm}$ calculated by Scherrer's formula $(d=k \lambda / \beta \cos \theta)$ based on the width at half maximum of peak (111) plane, indicating that increasing the capping amount helps to decrease the size of $\mathrm{ZnS}$ nanocrystals.

The capping amount of ME on ZnS NPs was determined by thermogravimetric analysis, and the curves were shown in Figure 1(e). The weight loss of $\mathrm{ZnS}_{1-3}$ is, respectively, $4.31 \%$, $3.88 \%$, and $1.43 \%$ at the temperature from 100 to $200^{\circ} \mathrm{C}$ that may be ascribed to residual solvent. Thiols like mercaptoethanol have the property of getting tightly adsorbed on the surface of the clusters, which can be decomposed at about $200^{\circ} \mathrm{C}$ [23]. Therefore, the rapid weight loss from $200^{\circ} \mathrm{C}$ to $325^{\circ} \mathrm{C}$ can be ascribed to the loss of tightly absorbed ME molecule on $\mathrm{ZnS}$ surface, and the weight loss of $\mathrm{ZnS}_{1-3}$ is, respectively, $23.59 \%, 27.7 \%$, and $33.84 \%$ at the temperature range. Additionally, the decompose temperature of ME from ZnS surface decreases as the increment of added ME during ME-capped ZnS synthesis, indicating a more tight absorb ability of ME on the surface of ZnS NPs capping a smaller amount of ME. The content of pure $\mathrm{ZnS}$ in ME-capped $\mathrm{ZnS}_{1-3}$ nanoparticles is, respectively, 69.78\%, $66.99 \%$, and $62.63 \%$, indicating that a large amount of capping agent exist still on the ZnS surface although greatly decreased the amount of added capping agent in the process of synthesis.

All three kinds of $\mathrm{ZnS}$ can be dispersed in DMF to obtain clear solution. The apparent RI of the DMF solution of MEcapped $\mathrm{ZnS}$ was shown in Figure 1(f). It can be seen that $\mathrm{ZnS}$ with $33.01 \mathrm{wt} \%$ capping amount has a higher apparent RI value than $\mathrm{ZnS}$ with higher or lower capping amount of $\mathrm{ME}$ at the same ME-capped ZnS content in DMF. This may be ascribed to its inhomogeneous particle size distribution 


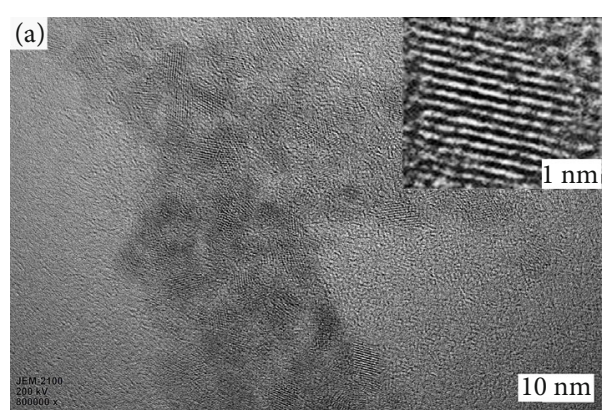

(a)

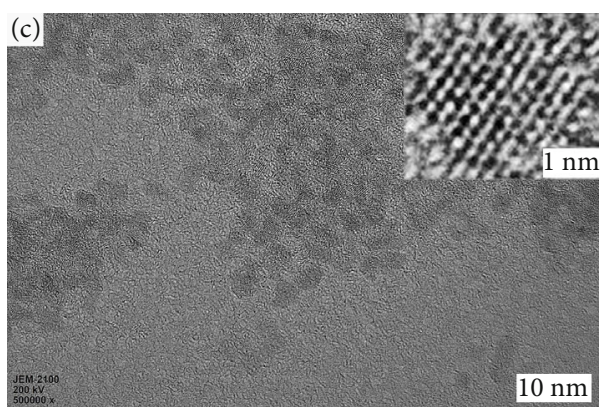

(c)

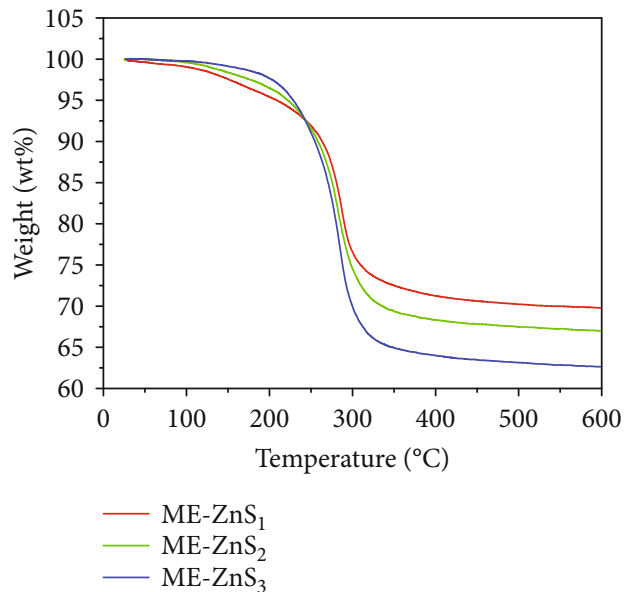

(e)



(b)


(d)



(f)

FIGURE 1: ZnS NPs capping different amount of mercaptoethanol. High-resolution transmission electron microscopy (HRTEM) image of $\mathrm{ZnS}_{1}(\mathrm{a}), \mathrm{ZnS}_{2}$ (b), and $\mathrm{ZnS}_{3}$ (c). XRD patterns (d) and TGA curves (e) of ZnS NPs. Apparent refractive index (f) of DMF solution of ME-capped ZnS NPs versus mass fraction of ME-capped ZnS NPs.

of $\mathrm{ZnS}_{2} \mathrm{NP}$, in which bigger size has a greater contribution to RI value.

3.2. Pure DMA-Type Copolymeric Nanocomposite Hydrogels from Polymerizable-Group-Capped ZnS. ZnS NPs have been embedded physically into DMA-based polymeric matrices. Herein, we bond covalently ZnS NPs on the polymeric matri- ces. To achieve this, polymerizable-group-capped ZnS NPs capping different amount of ME were synthesized by our previous method $[17,18]$. However, polymerizable-groupcapped $\mathrm{ZnS}$ capping low ME amount can not be dispersed in DMF and the monomer of DMA. The copolymeric hydrogels from polymerizable-group-capped $\mathrm{ZnS}$ with middle capping amount of $\mathrm{ME}\left(\mathrm{ZnS}_{2}\right)$ shows obvious Tyndall scattering 
effect when added $\mathrm{ZnS}_{2}$ is more than $30 \mathrm{wt} \%$ as shown in Figure 2(a), and its transmittance decreases greatly with increased $\mathrm{ZnS}_{2}$ as shown in Figure 2(b). However, The copolymeric hydrogels from polymerizable-group-capped $\mathrm{ZnS}$ capping high $\mathrm{ME}$ content $\left(\mathrm{ZnS}_{3}\right)$ are transparent at hydrated and dried state. Its transmittance slightly decreases with the increment of $\mathrm{ZnS}_{3}$ content especially in the wavelength between $300 \mathrm{~nm}$ and $400 \mathrm{~nm}$ as shown in Figure 2(c). The transmittance loss is mainly ascribed to the light scattering of the particles in nanocomposites. The relation between light intensity and nanoparticle size abides by Rayleigh's law as follows:

$$
I=I_{0} \exp \left[-\frac{3 \phi l R^{3}}{4 \lambda^{4}}\left(\frac{n_{N P}}{n_{p}}-1\right)\right]
$$

where $I_{0}$ and $I$ are the intensity of the incident and scattered light, $\phi$ is the volume fraction of the particles, $L$ means the thickness of the nanocomposite film, and $\lambda$ is the wavelength of the incident light. $n_{N P}$ and $n_{P}$ are the refractive index of nanoparticles and the polymer matrix in the nanocomposite films, respectively. The nanocomposite films should be highly transparent when the nanoparticle size is less than $40 \mathrm{~nm}$. The size of our $\mathrm{ZnS}_{1-3}$ is about $3 \mathrm{~nm}$, far less than $40 \mathrm{~nm}$, and the thickness is about $160 \mu \mathrm{m}$. The RI values of polymeric matrices of PDMA and $\mathrm{ZnS}$ nanocrystal are about 1.5 and 2.5, respectively. The volume fraction of the $\mathrm{ZnS}$ nanoparticles is less than $20 \%$. It can be calculated that the loss of light intensity from particle scattering should be less than $1 \%$ according to the Rayleigh's law. Therefore, it can be concluded that $\mathrm{ZnS}_{2}$ nanoparticle aggregates in the nanocomposite films; although, $\mathrm{ZnS}_{2}$ particles are also pendant on polymer chain by copolymerization [24].

RI value of hydrated hydrogels is highly correlated with its water content [25] and has been widely used to estimate its water loss in contact lens application [26]. For swollen hydrogel, its RI value is usually low because of the low RI value of polymeric matrices and water in the hydrogel. As shown in Figure 2(d), the RI value increases with improved $\mathrm{ZnS}$ content, which can be ascribed to decreased water content (Figure 2(d)) and improved high RI ZnS NPs content. In the hydrogels with high water content, polymer backbone has usually little influence on its RI value. Therefore, its RI value can be calculated according to their water content [27]. The hydrogel by copolymerization between polymerizable-group-capped $\mathrm{ZnS}$ has a higher RI value compared to reported hydrogels with a similar water content, e.g., the RI value of hydrogel with $30 \mathrm{wt} \% \mathrm{ZnS}$ (ESR: about $70 \%$, RI: about 1.39) is higher than that of Nefilcon A hydrogel (ESR: 69\%, RI: 1.38); the RI value of hydrogel with $50 \mathrm{wt} \%$ ZnS NPs (ESR: about 47\%, RI: 1.46) is higher than that of polymacon hydrogel (water content: $38.6 \%$, RI: 1.43). All these indicate that ZnS NPs in the nanocomposite hydrogels play a more important role on increasing RI value than decreased water content in the hydrogels. Moreover, it is unexpected that the RI value of the hydrogels compositing $\mathrm{ZnS}_{3}$ is higher than that of the hydrogel compositing a same content of $\mathrm{ZnS}_{2}$; although, the $\mathrm{ZnS}_{2}$ shows a higher refractive index than $\mathrm{ZnS}_{3}$ at the same mass concentration in DMF as shown in Figure 1(g). This can be explained by its more serious microphase separation of $\mathrm{ZnS}_{2}$ compositing hydrogels, which results in a higher water content as shown in Figure 2(d).

All hydrogels with different $\mathrm{ZnS}$ content shows highelastic state as shown in Figures 2(e) and 2(f), and their Young's modulus increasing as improved $\mathrm{ZnS}$ content, indicating polymerizable-group-capped $\mathrm{ZnS}$ act as crosslinker in the hydrogels. Moreover, the hydrogels with $\mathrm{ZnS}_{3}$ shows better mechanical properties, e.g., higher tensile strength and Young's modulus, longer elongation at break.

3.3. “One-Step” Route for Pure DMA-Type Nanocomposite Hydrogels. In order to composite ZnS NPs capping low amount of $\mathrm{ME}\left(\mathrm{ZnS}_{1}\right)$ into transparent nanocomposite film, a novel and simple "one-step" route was developed. In the route, ZnS NPs capping different amount of ME were directly dispersed in a mixture of DMF and DMA, and then, functional monomer of GMA and initiator of AIBN were added and dispersed by ultrasound after every addition. The polymerizable solution can be polymerized by a simple thermal curing process. We suppose the reaction mechanism as illustrated in Figure 3(a). Radical polymerization undergoes a relative slow chain initiation process [28], in which GMA is linked on $\mathrm{ZnS}$ surface under the catalysis of solvent DMF to obtain polymerizable $\mathrm{ZnS}$ that then copolymerized with monomer of DMA. To confirm further the reaction mechanism, the polymerization solution without initiator of AIBN was placed in $50^{\circ} \mathrm{C}$ oven for $3 \mathrm{~h}$, and then, $\mathrm{ZnS}$ NPs were precipitated in excess ethanol, and its chemical structure was confirmed by ${ }^{1} \mathrm{H}$ NMR spectra. As shown in Figure 3(b), obvious carbon-carbon double bond peaks, locating at $\delta=$ 6.11 and $5.57 \mathrm{ppm}$, were observed, confirming the grafting reaction mechanism of GMA on ME-capped $\mathrm{ZnS}$ surface in DMF solution.

It can be seen that the nanocomposite film compositing $\mathrm{ZnS}$ NPs capping low amount of $\mathrm{ME}\left(\mathrm{ZnS}_{1}\right)$ shows even a higher transmittance than that of the nanocomposite compositing ZnS NPs capping high amount of $\mathrm{ME}\left(\mathrm{ZnS}_{3}\right)$ as shown in Figures 4(a) and 4(c). Moreover, it is interesting that the nanocomposite films with $60 \mathrm{wt} \%$ and $70 \mathrm{wt} \% \mathrm{ME}-$ $\mathrm{ZnS}$ show higher transmittance than that of the nanocomposites with $40 \mathrm{wt} \%$ and $50 \mathrm{wt} \% \mathrm{ME}-\mathrm{ZnS}$. The mechanical properties of "one-step" nanocomposites were shown in Figures 4(d)-4(f). Obviously, the tensile strength and Young's modulus are higher than that of the copolymeric DMA-type nanocomposites from polymerizable-groupcapped ZnS (Figures 2(e) and 2(f)), indicating higher crosslink density of "one-step" nanocomposites ascribe to the chemical link of two GMA molecules due to epoxy group of a GMA molecule reaction with the hydroxyl group of the other GMA molecule that is formed from GMA link onto ME-ZnS surface.

High RI ZnS/PDMA hydrogels have been reported [12], and its RI can be regulated from 1.58 to 1.70 in the dry states. Obviously, dry ZnS/PDMA hydrogels fabricated by "onestep" route can achieve a higher RI value above 1.73 by compositing more amount ZnS NPs. Moreover, dry “one- 


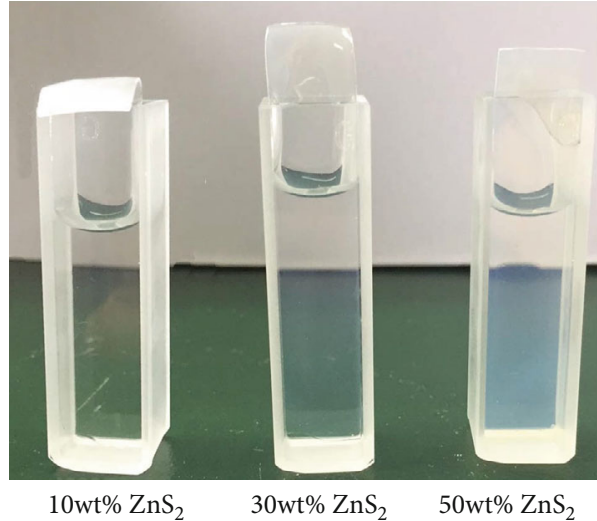

(a)

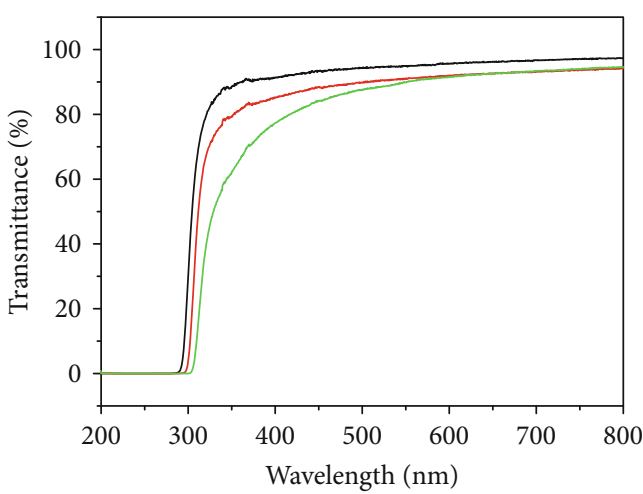

$0 \mathrm{wt} \% \mathrm{ZnS}_{3}$-DMA hydrogel $0 \mathrm{wt} \% \mathrm{ZnS}_{3}$-DMA hydrogel - $50 \mathrm{wt} \% \mathrm{ZnS}_{3}$-DMA hydrogel

(c)

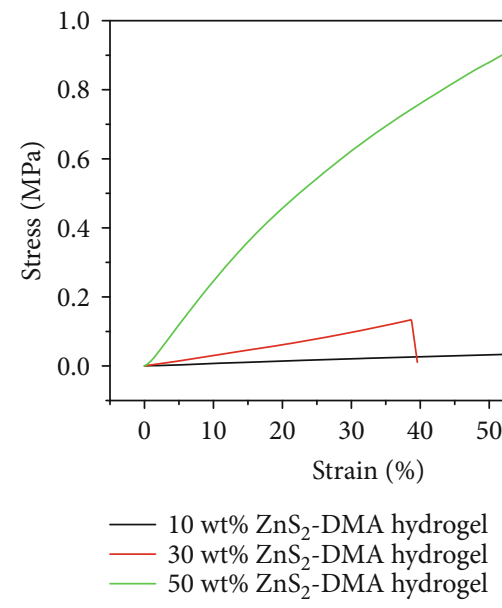

(e)

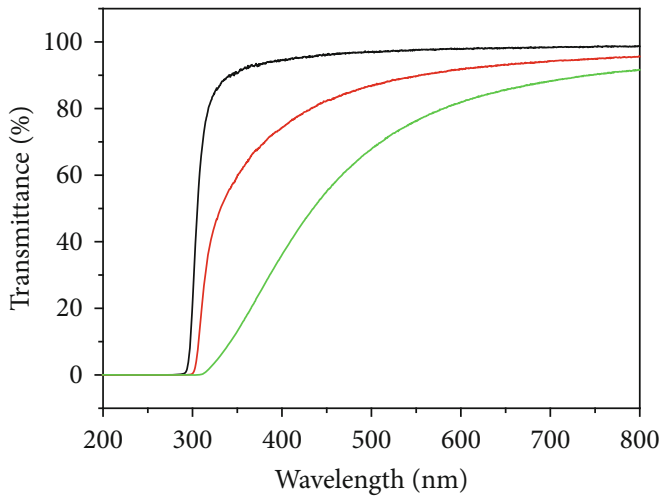

$0 \mathrm{wt} \% \mathrm{ZnS}_{2}$-DMA hydrogel

$30 \mathrm{wt} \% \mathrm{ZnS}_{2}$-DMA hydrogel

- $50 \mathrm{wt} \% \mathrm{ZnS}_{2}$-DMA hydrogel

(b)



- $\mathrm{RI}$ of $\mathrm{ZnS}_{2}$-DMA hydrogel

$\square$ RI of $\mathrm{ZnS}_{3}$-DMA hydrogel

- Water content of $\mathrm{ZnS}_{2}$-DMA hydrogel

○ Water content of $\mathrm{ZnS}_{3}$-DMA hydrogel

(d)

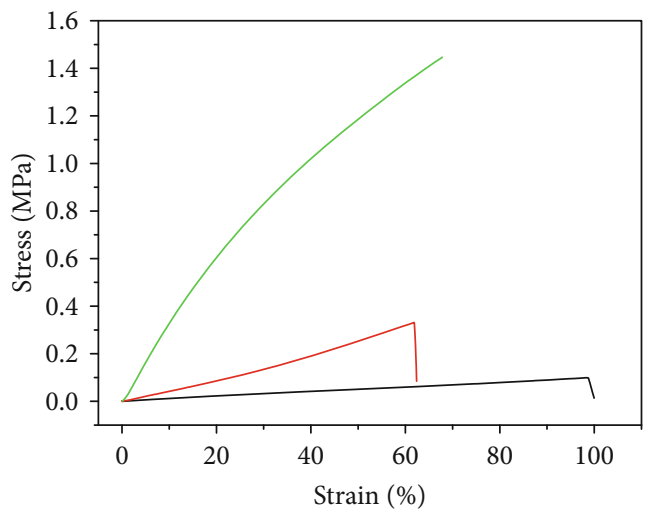

$10 \mathrm{wt} \% \mathrm{ZnS}_{3}$-DMA hydrogel
$-30 \mathrm{wt} \% \mathrm{ZnS}_{3}$-DMA hydrogel
$-50 \mathrm{wt} \% \mathrm{ZnS}_{3}$-DMA hydrogel

(f)

Figure 2: Pure DMA-type nanocomposite films from copolymerization between polymerizable-group-capped ZnS and the monomer of DMA. Photograph of hydrated nanocomposite hydrogels immersed in distilled water (a). Transmittance of the hydrated nanocomposite hydrogels compositing $\mathrm{ZnS}_{2}$ (b) and $\mathrm{ZnS}_{3}$ (c). Water content and refractive index of hydrated nanocomposite hydrogels (d). Stress-strain curve of hydrated nanocomposite hydrogels compositing $\mathrm{ZnS}_{2}$ (e) and $\mathrm{ZnS}_{3}$ (f). 


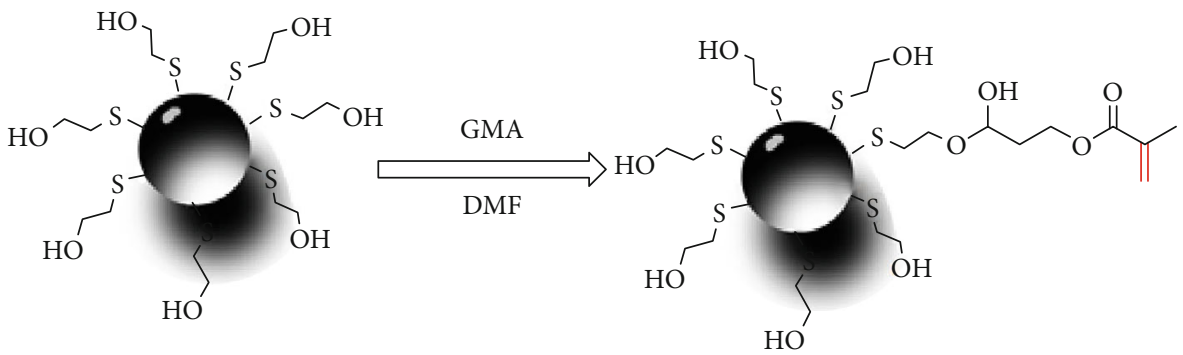

(a)



(b)

FIgURE 3: Synthesis route (a) between ME-capped ZnS and glycidyl methacrylate in "one-step" fabrication of nanocomposite films. ${ }^{1} \mathrm{H}$ NMR spectra (b) of ME-capped ZnS (A) and reaction product (B) between ME-ZnS and GMA.

step" $\mathrm{ZnS}_{2}$ nanocomposite film shows a higher $\mathrm{RI}$ value about 1.764 than $\mathrm{ZnS}_{1}$ and $\mathrm{ZnS}_{3}$ nanocomposite films (about 1.73) as shown in Figure 4(g), indicating a contrary regulation of pure $\mathrm{ZnS}$ and capping agent on the RI value. Higher RI films (about 1.645) with low $\mathrm{ZnS}$ content (less than $50 \mathrm{wt} \%$ ) can also be achieved by compositing ZnS NPs in high RI polystyrene. However, styrene monomer only can be used as comonomer of DMA monomer due to phase separation. There is no obvious difference among the water content of three kinds of hydrated nanocomposite with a similar $\mathrm{ZnS}$ content, and the typical relation between water conten$\mathrm{t} /$ refractive index and free $\mathrm{ME}-\mathrm{ZnS}$ content was shown in Figure 4(h). It seems that "one-step" nanocomposite hydrogels show lower water content than copolymeric hydrogels from polymerizable-group-capped $\mathrm{ZnS}$ (Figure 2(d)), resulting in a higher refractive index. This can be also ascribed to its higher crosslink density.

3.4. "One-Step" Route for DMA-Type Copolymeric Nanocomposite Hydrogels. To observe the applicability of "one-step" route for transparent nanocomposites, ZnS NPs capping different amount of ME were also incorporated into poly(HEMA-DMA) based copolymer matrices (DMA-type copolymer nanocomposite hydrogels). We found that the functional monomer of GMA plays an important role for its transmittance, e.g., the DMA-type copolymeric nanocomposite hydrogel, without adding functional monomer of GMA, exhibits serious irregular nanoparticle aggregation.
This can be confirmed by its TME photography and its opaque appearance as an inserted image as shown in Figure 5(a). However, "one-step" route greatly overcomes microphase separation; although, only a small quantity of functional monomer was added. The uniform dispersibility of $\mathrm{ZnS}$ particles can be confirmed by their transparent appearance and TEM photography (Figure 5(b)-5(d)). Our previous study has shown that it is difficult to disperse more than $10 \mathrm{wt} \% \mathrm{ME}-\mathrm{ZnS}$ NPs in poly(HEMA-DMA) copolymeric matrices to prepare transparent nanocomposites [17]. Therefore, it can be concluded that the reaction between GMA and ME-capped $\mathrm{ZnS}$ is rapid enough that major MEcapped $\mathrm{ZnS}$ is conversed into polymerizable $\mathrm{ZnS}$ in the chain initiation process, ensuring almost all $\mathrm{ZnS}$ can be pendant on polymer chain in the next rapid polymerization process.

The transmittance of copolymer nanocomposite hydrogels was shown in Figures 6(a)-6(c). It can be seen that all the copolymer nanocomposite hydrogels show even a higher transmittance than pure DMA-type “one-step" nanocomposite hydrogels. This may be ascribed to its higher crosslink density. In the polymerizable solution composed of MEcapped $\mathrm{ZnS}$ NPs, the functional monomer of GMA, polymerizable monomer of HEMA and DMA, at least three kinds of reaction from opening epoxy of GMA monomer can be predicted: grafting reaction of GMA on ME-capped ZnS surface; linkage reaction between GMA and HEMA; chemical reaction between GMA and the products of the above two kinds of reactions. The latter two reactions will produce short chain 

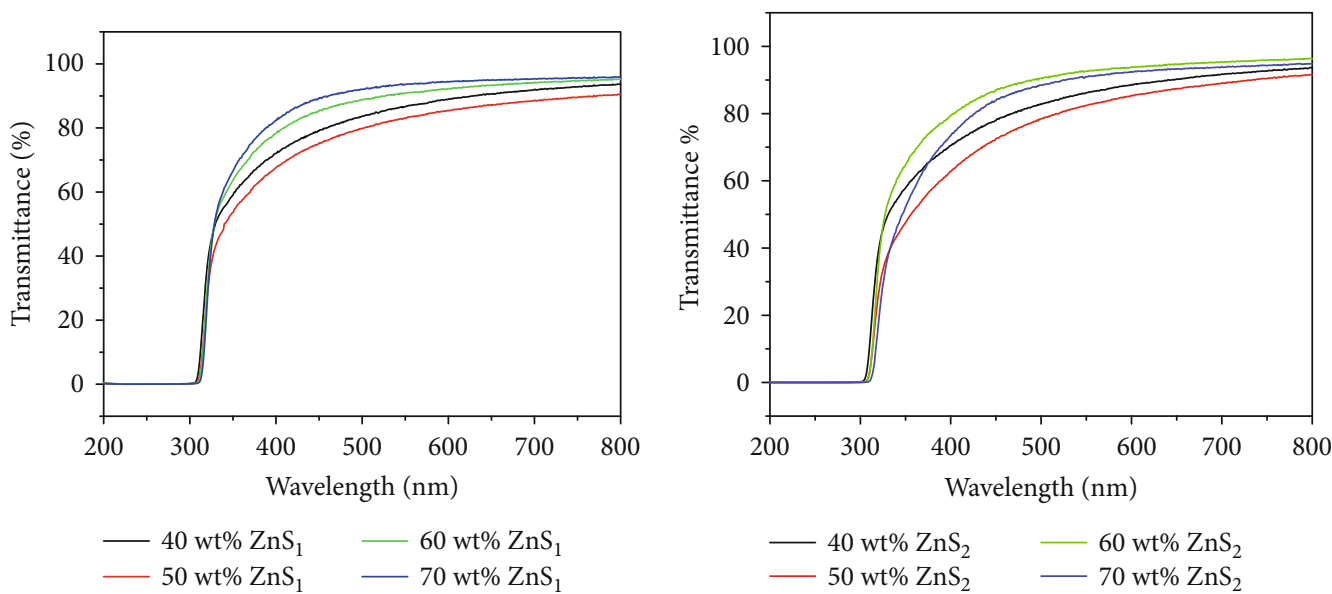

(a)
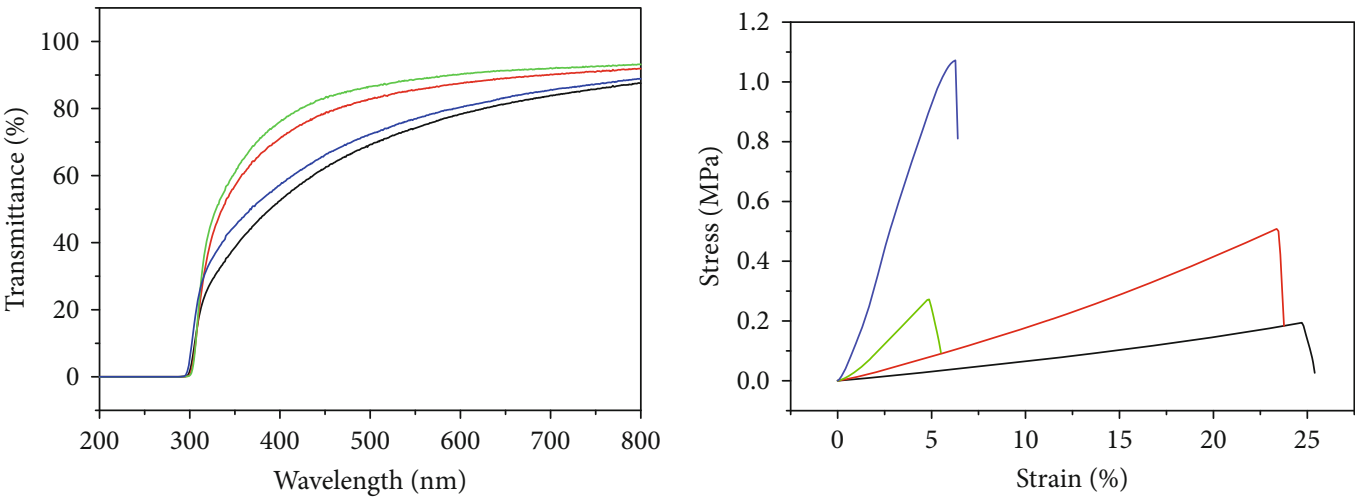

$-40 \mathrm{wt} \% \mathrm{ZnS}_{3} \quad-60 \mathrm{wt} \% \mathrm{ZnS}_{3}$
$-50 \mathrm{wt} \% \mathrm{ZnS}_{3} \quad-70 \mathrm{wt} \% \mathrm{ZnS}_{3}$

(c)

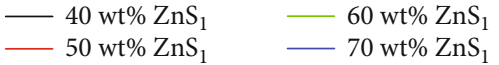

(d)
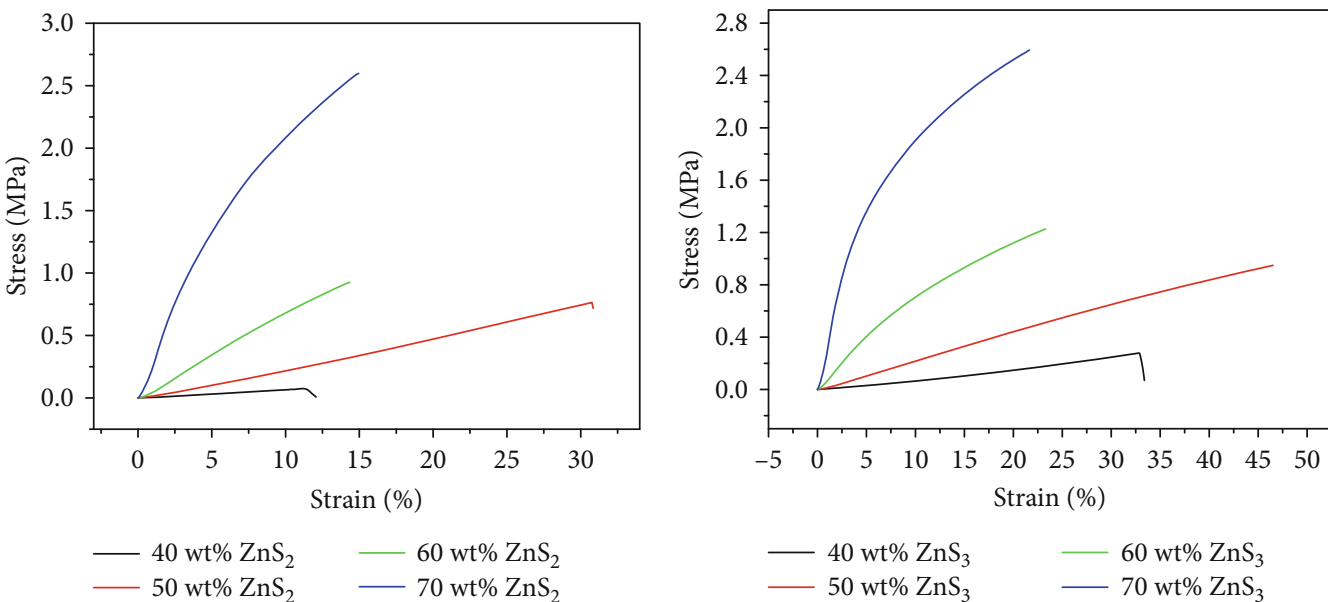

$40 \mathrm{wt} \% \mathrm{ZnS}_{2} \quad-60 \mathrm{wt} \% \mathrm{ZnS}_{2}$
$-50 \mathrm{wt} \% \mathrm{ZnS}_{2}$

(e)

(f)

FIgUre 4: Continued. 


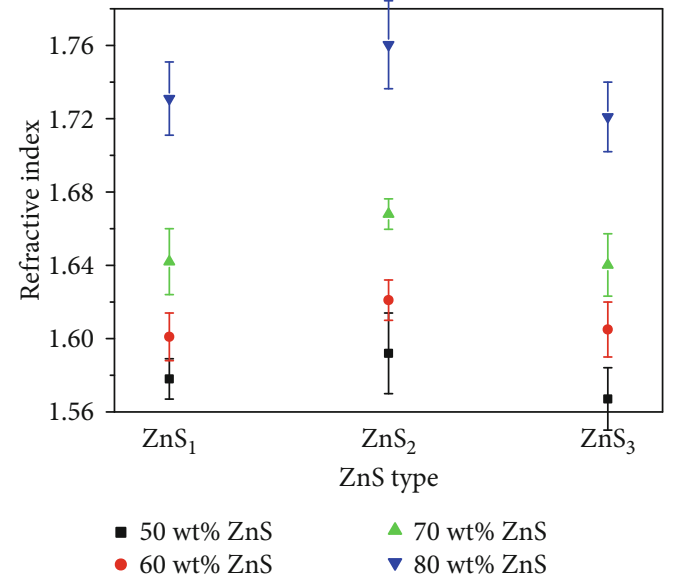

(g)

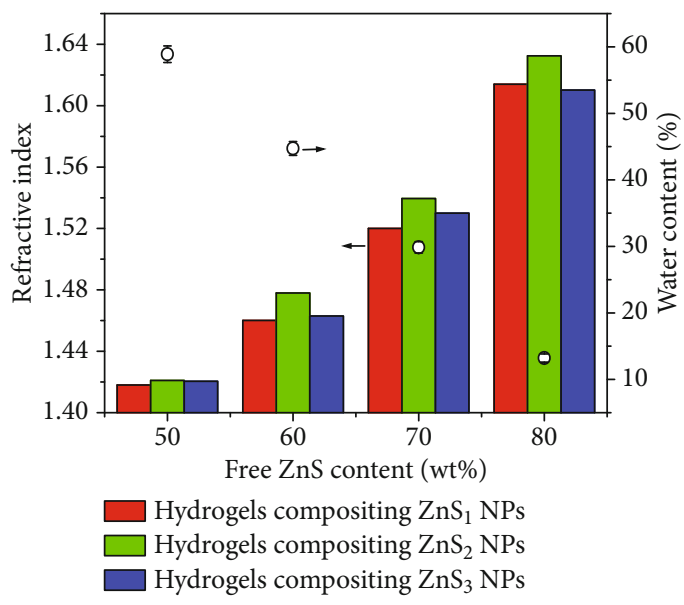

(h)

FIgure 4: Pure DMA-type “one-step” nanocomposite hydrogels. Transmittance of the hydrated hydrogels compositing $\mathrm{ZnS}_{1}$ (a), $\mathrm{ZnS}_{2}$ (b) and $\mathrm{ZnS}_{3}$ (c). Stress-strain curves of hydrated nanocomposite hydrogel compositing $\mathrm{ZnS}_{1}$ (d), $\mathrm{ZnS}_{2}$ (e) and $\mathrm{ZnS}$ (f). RI value of dried pure DMA-type nanocomposite films (g). Water content and RI value of hydrated nanocomposite hydrogels (h).

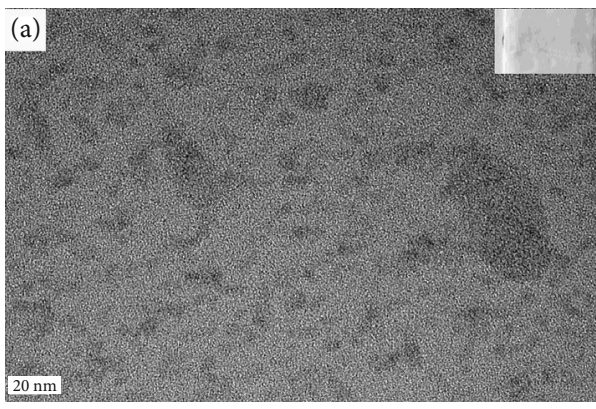

(a)

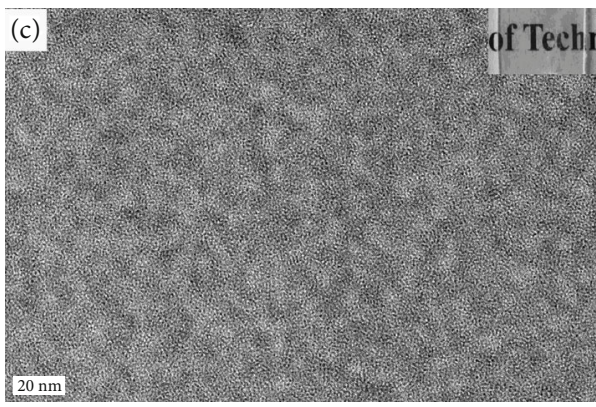

(c)

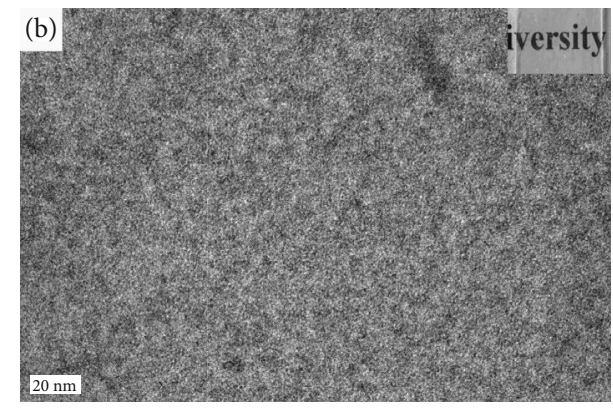

(b)

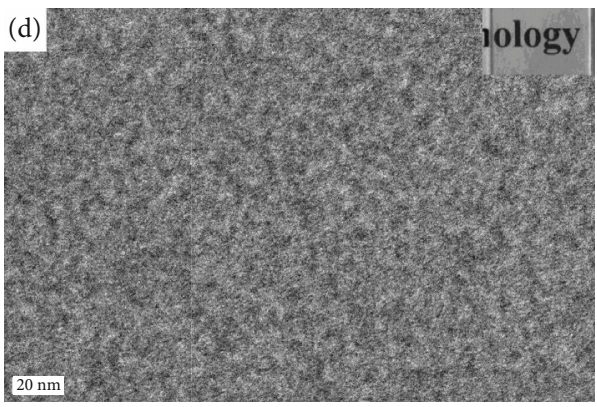

(d)

FIGURE 5: TEM photography of DMA-type copolymeric nanocomposite hydrogels and corresponding appearance as insert image. Hydrogels physically embedding $50 \mathrm{wt} \% \mathrm{ZnS}$ capping high amount of $\mathrm{ME}\left(\mathrm{ZnS}_{3}\right)$ without addition of functional monomer of GMA (a). Hydrogels compositing $50 \mathrm{wt} \% \mathrm{ZnS}_{1}$ (b), $50 \mathrm{wt} \% \mathrm{ZnS}_{2}$ (c), $50 \mathrm{wt} \% \mathrm{ZnS}_{3}$ (d) by "one-step" route characterized by adding functional monomer of GMA.

crosslinker, resulting in increased crosslink density in the nanocomposite films.

All hydrogels with different $\mathrm{ZnS}$ content show also highelastic state as shown in Figures 6(d)-6(f); although, the elongation at break is lower than that of pure DMA-type nanocomposite hydrogels from polymerizable-group-capped ZnS (Figures 2(e) and 2(f)). Young's modulus increasing as improved $\mathrm{ZnS}$ content, and the hydrogel with high $\mathrm{ZnS}$ content is obviously higher than that of poly(HEMA-DMA) nanocomposite hydrogels from polymerization between polymerizable-group-capped $\mathrm{ZnS}$ and the monomer of DMA and HEMA as our previous report [17]. This further confirms its higher crosslink density as mentioned above. The hydrogels with $\mathrm{ZnS}_{3}$ show higher tensile strength and Young's modulus, longer elongation at break than the hydrogels with $\mathrm{ZnS}_{1}$ or $\mathrm{ZnS}_{2}$.

The RI value and water content of the nanocomposite hydrogels after equilibrium in distilled water were shown in 

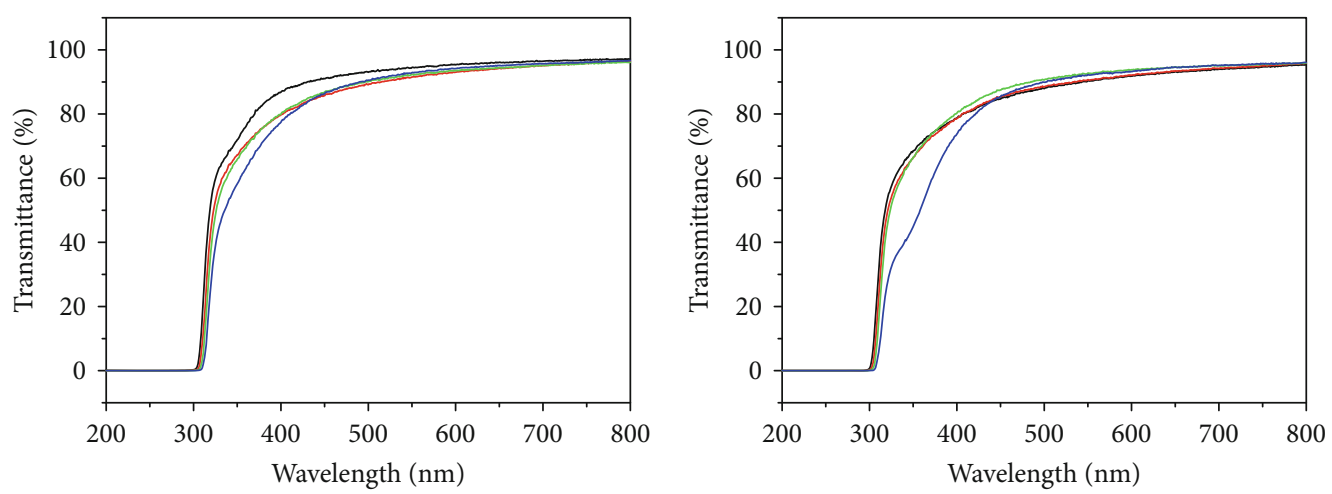

- Hydrogel with $30 \mathrm{wt} \% \mathrm{ZnS}$

Hydrogel with $40 \mathrm{wt} \% \mathrm{ZnS}_{1}$

Hydrogel with $50 \mathrm{wt} \% \mathrm{ZnS}_{1}$

— Hydrogel with $60 \mathrm{wt} \% \mathrm{ZnS}_{1}$

(a)

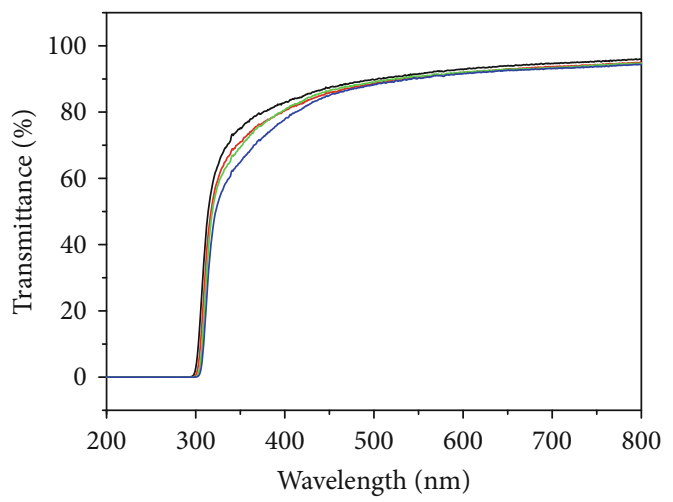

- Hydrogel with $30 \mathrm{wt} \% \mathrm{ZnS}_{2}$

- Hydrogel with $40 \mathrm{wt} \% \mathrm{ZnS}_{2}$

- Hydrogel with $50 \mathrm{wt} \% \mathrm{ZnS}_{2}$

- Hydrogel with $60 \mathrm{wt} \% \mathrm{ZnS}_{2}$

(b)

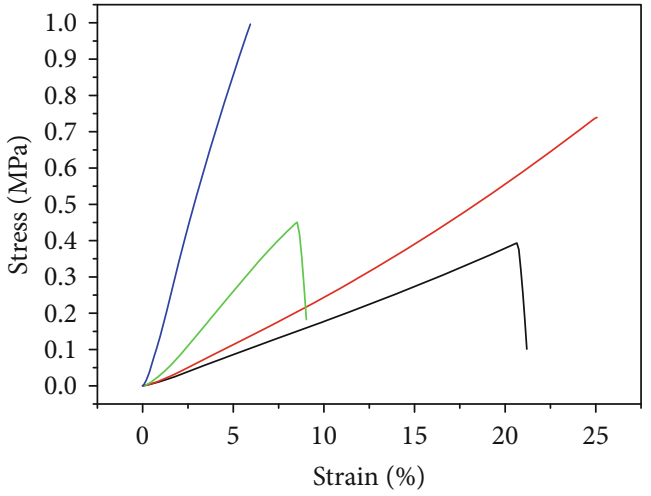

- Hydrogel with $30 \mathrm{wt} \% \mathrm{ZnS}_{3}$

- Hydrogel with $40 \mathrm{wt} \% \mathrm{ZnS}_{3}$

Hydrogel with $50 \mathrm{wt} \% \mathrm{ZnS}_{3}$

— Hydrogel with $60 \mathrm{wt} \% \mathrm{ZnS}_{3}$

(c)
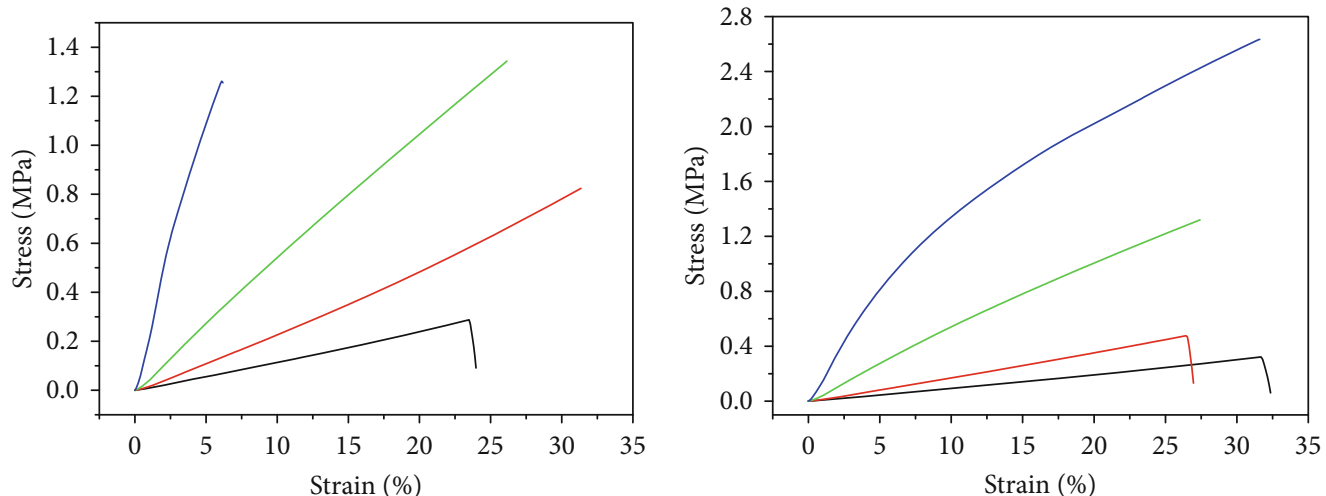

Hydrogel with $30 \mathrm{wt} \% \mathrm{ZnS}_{2}$

Hydrogel with $40 \mathrm{wt} \% \mathrm{ZnS}_{2}$

Hydrogel with $50 \mathrm{wt} \% \mathrm{ZnS}_{2}$

Hydrogel with $60 \mathrm{wt} \% \mathrm{ZnS}_{2}$

(e)

Figure 6: Continued. 


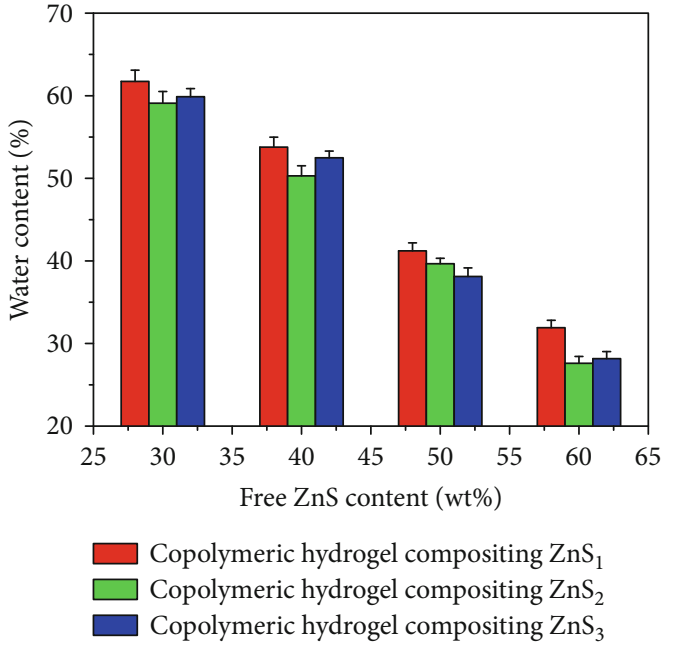

(g)

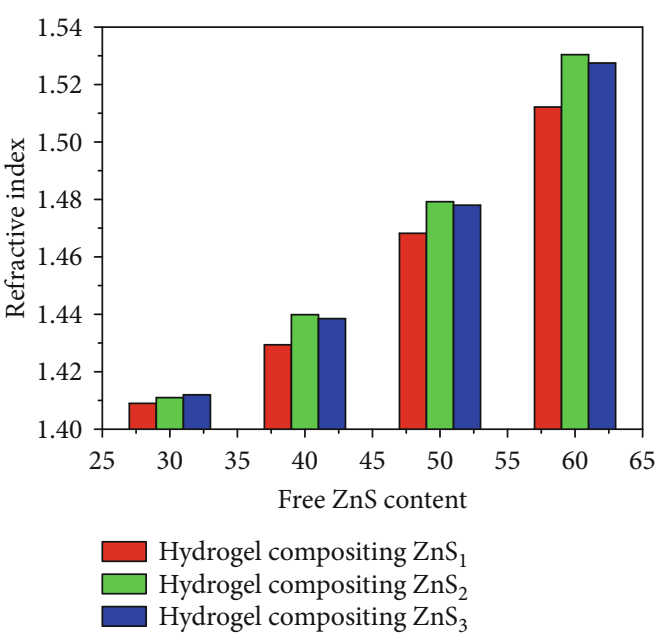

(h)

Figure 6: DMA-type copolymeric nanocomposite hydrogels by "one-step" route. Transmittance of the hydrated nanocomposite hydrogels compositing $\mathrm{ZnS}_{1}$ (a), $\mathrm{ZnS}_{2}$ (b), and $\mathrm{ZnS}_{3}$ (c). Stress-strain curves of hydrated nanocomposite hydrogel compositing $\mathrm{ZnS}_{1}$ (d), ZnS 2 (e), and $\mathrm{ZnS}_{3}(\mathrm{f})$. Water content $(\mathrm{g})$ and refractive index $(\mathrm{h})$ of hydrated nanocomposite hydrogels.

Figure $6(\mathrm{~g})$. There is no obvious difference was observed for the water content of three kinds of hydrogels. The incorporation of ZnS NPs in the hydrogel increases its refractive index, for example, the RI value reaches 1.52 when $\mathrm{ZnS}$ content is $60 \mathrm{wt} \%$. Moreover, similar to the RI value of pure DMAtype nanocomposite hydrogels, the nanocomposite film with $\mathrm{ZnS}_{2}$ possesses also higher RI value than the nanocomposite with $\mathrm{ZnS}_{1}$ and $\mathrm{ZnS}_{3}$.

3.5. “One-Step" Route for DMA-Free Nanocomposites. The route, "one-step" fabrication of transparent nanocomposites, was further used to prepare DMA-free nanocomposites (PMMA-based nanocomposites). We found the DMA-free nanocomposite is opaque using a similar process with DMA-type nanocomposites. This indicates that a small amount of ME-capped $\mathrm{ZnS}$ do not still react with GMA in chain initiation process. Therefore, an additional heat treatment $\left(50^{\circ} \mathrm{C}, 3 \mathrm{~h}\right)$ was performed after the addition of functional monomer of GMA in ZnS DMF solution. The polymerization solution can be cured to obtain transparent nanocomposites at $80^{\circ} \mathrm{C}$. This indicates that $\mathrm{ZnS}$ NPs can be uniformly dispersed in DMA-free polymeric nanocomposites by a simple adjustment of the "one-step" route. In addition, we also decreased the time of reaction solution in $50^{\circ} \mathrm{C}$ oven to $1 \mathrm{~h}$ and $2 \mathrm{~h}$. However, the resulting nanocomposites were still opaque, and the transmittance increases with extending the time of thermo-treatment. It seems that it is easier to synthesize transparent DMA-type copolymeric nanocomposites than DMA-free nanocomposites, and there is no additional process was set for the grafting reaction. This is mainly ascribed to the monomer of DMA that can play roles as both ligand and solvent effect, resulting effectively disperses and stabilizes ZnS particles. Moreover, it can also be concluded that part ME-capped $\mathrm{ZnS}$ was not pendant on polymeric matrices in DMA-type copolymeric nanocompos- ites, in which it was dispersed and stabilized by DMA component. The PMMA-based nanocomposite film compositing $\mathrm{ZnS}$ capping $33.01 \mathrm{wt} \% \mathrm{ME}\left(\mathrm{ZnS}_{2}\right)$ shows also an obvious higher RI value than that compositing $\mathrm{ZnS}$ capping higher and lower amount of ME as shown in Figure 7. This is also consistence with the data of pure DMA-type nanocomposites. Poly(methyl methacrylate) is a key polymer component for nanocomposite filling quantum dots because of its unique properties including excellent transmittance from the near UV that helps more energy can be absorbed by quantum dots under UV irradiation, maintaining the photophysics associated with the photoexcited states of the crystallites in the nanocomposites. Herein, the PMMA-based nanocomposites by the novel "one-step" route also show a good photoluminescence property under UV-irradiation as shown in Figure 7.

\section{Conclusions}

The amount of capping mercaptoethanol on $\mathrm{ZnS}$ surface can be controlled by adjusting the amount of mercaptoethanol added in the synthesis process, and increased capping amount helps to decrease the size of $\mathrm{ZnS}$ nanocrystals. The apparent refractive index of $\mathrm{ZnS}$ with middle capping amount of ME (27.7 wt\%) shows a higher RI value than that of $\mathrm{ZnS}$ NPs with lower (23.6 wt\%) or higher (33.8 wt\%) capping amount of ME, ZnS NPs capping different amount of ME were successfully composited into polymeric matrices by a simple "one-step" thermocuring method characterized by the addition of a small amount of functional monomer of GMA. Epoxy group of GMA monomer can be easily opened and chemically grafted on ME-capped $\mathrm{ZnS}$ surface under the catalysis of solvent DMF in the relative slow chain initiation process of the polymerization, and then copolymerized with other monomers. By the route, $\mathrm{ZnS}$ 


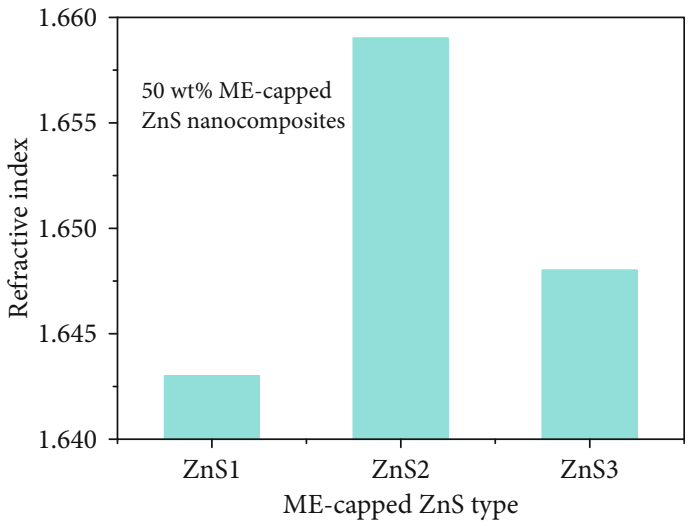

(a)

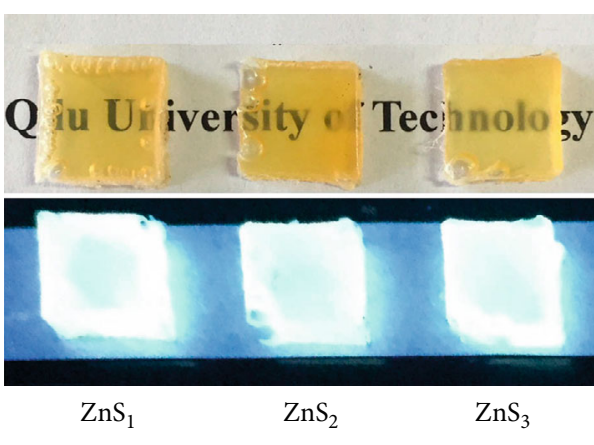

(b)

FIgURE 7: RI value of PMMA-based nanocomposites compositing $50 \mathrm{wt} \% \mathrm{ZnS}$ capping different amount of ME (a). Image of PMMA-based nanocomposites and its photoluminescence (PL) under UV illumination (b).

nanocrystals capping different amount of ME can be composited into pure DMA-type, DMA-type copolymer, and DMA-free polymeric matrices to prepare transparent and high refractive index nanocomposite films. The nanocomposite films compositing $80 \mathrm{wt} \%$ ZnS nanocrystals capping middle amount of ME shows a higher RI value (1.764) than the nanocomposites compositing the same amount of $\mathrm{ZnS}$ nanocrystals capping higher or lower amount of ME, indicating that the RI value of resulting nanocomposites can be improved by optimizing the capping amount on $\mathrm{ZnS}$ surface. The route is an obvious advantage over reported methods because of not only simple and universal but also higher refractive index and transparent nanocomposite films.

\section{Data Availability}

All data are available from the corresponding author by request.

\section{Conflicts of Interest}

The authors declare no conflict of interest.

\section{Acknowledgments}

The projects were supported by the Key Research and Development Program of Shandong Province (No. 2019GGX102042) and the Program of Jinan Academic Research Leader (No. 2019GXRC060).

\section{References}

[1] C. Lü and B. Yang, "High refractive index organic-inorganic nanocomposites: design, synthesis and application," Journal of Materials Chemistry, vol. 19, no. 19, p. 2884, 2009.

[2] F. W. Mont, J. K. Kim, M. F. Schubert, E. F. Schubert, and R. W. Siegel, "High-refractive-index TiO2-nanoparticleloaded encapsulants for light-emitting diodes," Journal of Applied Physics, vol. 103, no. 8, p. 083120, 2008.
[3] J. Liu and M. Ueda, "High refractive index polymers: fundamental research and practical applications," Journal of Materials Chemistry, vol. 19, no. 47, p. 8907, 2009.

[4] X. Hao, J. L. Jeffery, T. P. T. le et al., "High refractive index polysiloxane as Injectable, _in situ_ curable accommodating intraocular lens," Biomaterials, vol. 33, no. 23, pp. 5659$5671,2012$.

[5] J. Xu, W. Zhu, L. Jiang, J. Xu, Y. Zhang, and Y. Cui, "Carbazole-grafted silicone hydrogel with a high refractive index for intraocular lens," RSC Advances, vol. 5, no. 89, pp. 72736-72744, 2015.

[6] X. Lan, W. Huang, and Y. Yu, "Graphical Abstracts," European Polymer Journal, vol. 46, no. 1, pp. 1-4, 2010.

[7] B. Goswami, S. Pal, and P. Sarkar, "A Theoretical Study on the Electronic Structure of $\mathrm{ZnSe} / \mathrm{ZnS}$ and $\mathrm{ZnS} / \mathrm{ZnSe}$ Core/Shell Nanoparticles," Journal of Physical Chemistry C, vol. 112, no. 31, pp. 11630-11636, 2008.

[8] J. S. Steckel, J. P. Zimmer, S. Coe-Sullivan, N. E. Stott, V. Bulović, and M. G. Bawendi, "Preview: Angew. Chem. Int. Ed. 43/2004," Angewandte Chemie (International Ed. in English), vol. 43, no. 43, p. 5861, 2004.

[9] A. V. Baranov, Y. P. Rakovich, J. F. Donegan et al., "Effect of $\mathrm{ZnS}$ shell thickness on the phonon spectra in CdSe quantum dots," Physical Review B, vol. 68, no. 16, 2003.

[10] L. Li, T. J. Daou, I. Texier, T. T. Kim Chi, N. Q. Liem, and P. Reiss, "Highly Luminescent CuInS2/ZnS Core/Shell Nanocrystals: Cadmium-Free Quantum Dots for In Vivo Imaging," Chemistry of Materials, vol. 21, no. 12, pp. 2422-2429, 2009.

[11] Z. Fang, Y. Li, H. Zhang, X. Zhong, and L. Zhu, "Facile Synthesis of Highly Luminescent UV-Blue-Emitting ZnSe/ZnS Core/Shell Nanocrystals in Aqueous Media," The Journal of Physical Chemistry C, vol. 113, no. 32, pp. 14145-14150, 2009.

[12] Q. Zhang, K. Su, M. B. Chan-Park, H. Wu, D. Wang, and R. Xu, "Development of high refractive ZnS/PVP/PDMAA hydrogel nanocomposites for artificial cornea implants," Acta Biomaterialia, vol. 10, no. 3, pp. 1167-1176, 2014.

[13] Y. Yin and A. P. Alivisatos, "Colloidal nanocrystal synthesis and the organic-inorganic interface," Nature, vol. 437, no. 7059, pp. 664-670, 2005.

[14] N. Pradhan, D. Reifsnyder, R. Xie, J. Aldana, and X. Peng, "Surface Ligand Dynamics in Growth of Nanocrystals," 
Journal of the American Chemical Society, vol. 129, no. 30, pp. 9500-9509, 2007.

[15] X. Ji, D. Copenhaver, C. Sichmeller, and X. Peng, "Ligand Bonding and Dynamics on Colloidal Nanocrystals at Room Temperature: The Case of Alkylamines on CdSe Nanocrystals," Journal of the American Chemical Society, vol. 130, no. 17, pp. 5726-5735, 2008.

[16] J. Nanda, S. Sapra, D. D. Sarma, N. Chandrasekharan, and G. Hodes, "Size-Selected Zinc Sulfide Nanocrystallites: Synthesis, Structure, and Optical Studies," Chemistry of Materials, vol. 12, no. 4, pp. 1018-1024, 2000.

[17] J. Xu, Y. Zhang, W. Zhu, and Y. Cui, "Synthesis of Polymeric Nanocomposite Hydrogels Containing the Pendant ZnS Nanoparticles: Approach to Higher Refractive Index Optical Polymeric Nanocomposites," Macromolecules, vol. 51, no. 7, pp. 2672-2681, 2018.

[18] P. Zhao, J. Xu, Y. Zhang, W. Zhu, and Y. Cui, "Polymerizablegroup capped $\mathrm{ZnS}$ nanoparticle for high refractive index inorganic-organic hydrogel contact lens," Materials Science and Engineering: C, vol. 90, pp. 485-493, 2018.

[19] Y. Gao and X. Peng, "Crystal Structure Control of CdSe Nanocrystals in Growth and Nucleation: Dominating Effects of Surface versus Interior Structure," Journal of the American Chemical Society, vol. 136, no. 18, pp. 6724-6732, 2014.

[20] F. Wang, V. N. Richards, S. P. Shields, and W. E. Buhro, "Kinetics and Mechanisms of Aggregative Nanocrystal Growth," Chemistry of Materials, vol. 26, no. 1, pp. 5-21, 2013.

[21] K. Murakoshi, H. Hosokawa, N. Tanaka et al., "Phase transition of $\mathrm{ZnS}$ nanocrystallites induced by surface modification at ambient temperature and pressure confirmed by electron diffraction," Chemical Communications, vol. 3, no. 3, pp. 321-322, 1998.

[22] Y. Nosaka, K. Yamaguchi, H. Miyama, and H. Hayashi, "Preparation of Size-Controlled CdS Colloids in Water and Their Optical Properties," Chemistry Letters, vol. 17, no. 4, pp. 605-608, 1988.

[23] L. L. Beecroft and C. K. Ober, "Nanocomposite Materials for Optical Applications," Chemistry of Materials, vol. 9, no. 6, pp. 1302-1317, 1997.

[24] G. Y. Mousa, M. G. Callender, J. G. Sivak, and D. J. Edan, “The effect ofindex hydratation caracteristics of hydrogel lenses on the re-fractive index," Contact Lens Clinic, vol. 10, pp. 31-37, 1983.

[25] P. B. Morgan and N. Efron, "Hydrogel contact lens ageing," The CLAO Journal, vol. 26, pp. 85-90, 2000.

[26] J. M. González-Méijome, A. López-Alemany, M. Lira, J. B. Almeida, M. E. C. D. R. Oliveira, and M. A. Parafita, "Equivalences between refractive index and equilibrium water content of conventional and silicone hydrogel soft contact lenses from automated and manual refractometry," Journal of Biomedical Materials Research Part B: Applied Biomaterials, vol. 80B, no. 1, pp. 184-191, 2007.

[27] J. Xu, P. Yang, L. Zhang, and G. Huo, "Radical/Addition polymerization silicone hydrogels with simultaneous interpenetrating hydrophilic/hydrophobic networks," Journal of Applied Polymer Science, vol. 132, no. 5, 2015.

[28] C. Lü, Y. Cheng, Y. Liu, F. Liu, and B. Yang, "A Facile Route to ZnS-Polymer Nanocomposite Optical Materials with High Nanophase Content via $\gamma$-Ray Irradiation Initiated Bulk Polymerization," Advanced Materials, vol. 18, no. 9, pp. 11881192, 2006. 